\title{
Feasibility and Aesthetic Results of Small Bilateral V-Y Advancement Flaps in the Extremities and Back
}

\author{
Dong Yeon Kim, Jong Hyun Choi, \\ Suk-Ho Moon, Deuk Young Oh \\ Department of Plastic and Reconstructive \\ Surgery, Seoul St. Mary's Hospital, College \\ of Medicine, The Catholic University of \\ Korea, Seoul, Korea
}

\begin{abstract}
Background Random type small V-Y advancement flap is widely used for facial reconstruction with advantages including good color and texture match. However, the flap is not as widely used in the extremities and back as in the face because of apprehension of the relatively poor vascularity as a risk factor of flap necrosis. We used a small bilateral V-Y advancement flap for the repair of extremity and back defects from various causes. Competent clinical outcomes are described.

Methods Between 2007 and 2014, 24 patients (48 flaps) with skin defects in the upper or lower extremities and back were enrolled. The site of the defect was on back $(n=6)$, forearm $(n=7)$, upper arm $(n=2)$, lower leg $(n=5)$, thigh $(n=3)$, and axilla $(n=1)$.

Results Among the 48 flaps, 47 survived (no event: 42 flaps, total necrosis: 1 flap, partial necrosis: 5 flaps). All partial necrotized flaps healed in 3-4 weeks with conservative care. However, debridement and skin grafting was required for the total necrosis flap. One total necrosis and two partial necroses occurred on the anterolateral side of the lower leg. Two partial necroses occurred on the paraspinal area.

Conclusions Contour deformities including central depression and the dog-ear deformity were not observed. Small bilateral $V-Y$ advancement in the extremity and back could be a safe and useful flap, if thick subcutaneous fat and subcutaneous plexus were saved. But areas with thin subcutaneous fat layer, such as the anterolateral lower leg, are poor candidates and carry the increased risk of improper subcutaneous pedicle circulation.
\end{abstract}

Keywords Extremities, Reconstructive surgical procedures, Surgical flaps
No potential conflict of interest relevant to this article was reported. defect is also removed, and it can leave a central depression with dog ears at its ends. Furthermore, these problems are exacerbated when an elliptical excision is performed in a region with insufficient skin redundancy, such as the pretibial region or the heel.

Bilateral V-Y advancement flaps have been widely used to reconstruct facial defects $[1,2]$. These flaps simplify and ease mapping and the operative procedure. Moreover, they show good color and texture harmony because nearby tissue is used. In this technique, triangular flaps based on nutrient pedicles in subcutaneous tissue are usually elevated. Although these random flaps have been proven to have excellent vascularity in the facial region $[3,4]$, repair of the extremities using these flaps has been regarded as more difficult than reconstructions elsewhere in the body because of poor blood supply and the pressure effects of dependency [5]. We performed bilateral V-Y advancement flaps in 24 patients with small
Received: Sep 18, 2017 Revised: Sep 30, 2017 Accepted: Oct 2, 2017

Correspondence: Deuk Young Oh Department of Plastic and Reconstructive Surgery, Seoul St. Mary's Hospital, College of Medicine, Catholic University of Korea, 222 Banpo-daero, Seocho-gu, Seoul 06591, Korea.

E-mail: ohdeuk1234@hanmail.net

Copyright @ 2017 The Korean Society for Aesthetic Plastic Surgery.

This is an Open Access article distributed under the terms of the Creative Commons At tribution Non-Commercial License (http://creativecommons.org/licenses/by-nc/4.0/) which permits unrestricted non-commercial use, distribution, and reproduction in any medium, provided the original work is properly cited. $\quad$ www.e-aaps.org 
skin defects $\left(1.0 \mathrm{~cm}^{2}-10 \mathrm{~cm}^{2}\right)$ in the back and extremities and achieved satisfactory results, but also found some discouraging cases depending on the location of the defect. Herein, we would like to describe our technique and its clinical outcomes.

\section{METHODS}

This procedure was performed on 24 patients (14 males and $10 \mathrm{fe-}$ males) who visited our hospital between May 2007 and March 2014. The patients' charts were reviewed and information regarding patient demographics, diagnosis, location of the lesion, defect size, any complications, and the course of follow-up was recorded (Table 1). The patients were 7 to 76 years of age, with a mean age of 40.2 years. The size of the defect ranged from 1.0 to $16 \mathrm{~cm}^{2}$, with a mean of $4.0 \mathrm{~cm}^{2}$. No patient had peripheral vascular disease or diabetes. Patients were also asked to complete a subjective self-assessment using a 4 -point scale ( -1 , unsatisfied; 0 , tolerable; 1 , satisfied; 2 , very satisfied).

\section{Surgical technique}

All procedures were performed under local anesthesia in an outpatient setting. The intended incision line was first marked. A fusiform elliptical excision line was designed, with its axis parallel to the skin tension line. After the skin pathology was completely removed, it was essential to match the size of the 2 triangular donor areas with the size of the defect area before flap elevation. The skin incision of the triangular flaps was then carried down to the subcutaneous layer in a columnar shape. The dissection was only carried out into the deep fat layer by releasing the superficial fascia layer. No surgical manipulation of the deep fascial system was necessary. Care was taken to keep the cross-sectional area of the subcutaneous pedicle wider than the triangular skin flap area. The skin flaps were advanced to the defect area with a skin hook to check the tension of the wound. Although skin undermining of the flap donor site was not needed in most cases, minimal undermining was performed if there was considerable tension or difficulty in flap sliding. The 2 flaps were subsequently sutured together in the middle with subcuticular and percutaneous sutures, and the 2 donor areas were sutured primarily.

Table 1. Summary of the characteristics of the patients

\begin{tabular}{|c|c|c|c|c|c|}
\hline No. & Sex/Age & Location & Size of the defect $\left(\mathrm{cm}^{2}\right)$ & Diagnosis & Complications \\
\hline 1 & $\mathrm{~F} / 70$ & Thigh & $4.0 \times 4.0$ & Abscess & \\
\hline 2 & $M / 27$ & Thigh & $3.0 \times 4.0$ & Dermatofibroma & \\
\hline 3 & $F / 47$ & Thigh & $1.2 \times 1.2$ & Dermatofibroma & \\
\hline 4 & $F / 9$ & Lower leg (posteromedial) & $1.2 \times 1.3$ & Hypertrophic scar & \\
\hline 5 & $\mathrm{~F} / 35$ & Lower leg (posteromedial) & $1.0 \times 1.0$ & Dermatofibroma & \\
\hline 6 & $M / 47$ & Lower leg (posteromedial) & $1.0 \times 1.0$ & Dermatofibroma & \\
\hline 7 & $\mathrm{~F} / 11$ & Lower leg (anterolateral) & $1.5 \times 1.5$ & Melanocytic nevus & Partial necrosis in 2 flaps \\
\hline 8 & $M / 40$ & Lower leg (anterolateral) & $2.5 \times 2.5$ & SCC & Total necrosis in 1 flap \\
\hline 9 & $M / 76$ & Axilla & $1.5 \times 1.5$ & EIC & \\
\hline 10 & $M / 18$ & Upper arm & $2.0 \times 3.0$ & Melanocytic nevus & \\
\hline 11 & $\mathrm{~F} / 73$ & Upper arm & $2.0 \times 2.0$ & Focal fibrosis & \\
\hline 12 & $M / 58$ & Forearm & $2.2 \times 1.1$ & $\mathrm{BCC}$ & \\
\hline 13 & $F / 14$ & Forearm & $2.0 \times 2.0$ & Melanocytic nevus & \\
\hline 14 & $M / 46$ & Forearm & $2.5 \times 1.5$ & Neurofibroma & \\
\hline 15 & $\mathrm{M} / 7$ & Forearm & $1.0 \times 1.0$ & Melanocytic nevus & \\
\hline 16 & $M / 51$ & Forearm & $1.5 \times 1.5$ & $\mathrm{BCC}$ & Partial necrosis in 1 flap \\
\hline 17 & $\mathrm{M} / 76$ & Forearm & $2.5 \times 2.0$ & Bowen disease & \\
\hline 18 & $\mathrm{~F} / 8$ & Forearm & $2.0 \times 1.0$ & Contact burn & \\
\hline 19 & $M / 28$ & Back & $1.5 \times 1.5$ & EIC & \\
\hline 20 & $M / 12$ & Back & $1.2 \times 1.2$ & Halo nevus & \\
\hline 21 & $M / 43$ & Back & $1.6 \times 1.6$ & EIC & Partial necrosis in 1 flap \\
\hline 22 & $M / 58$ & Back & $3.0 \times 3.0$ & Contact burn & \\
\hline 23 & $\mathrm{~F} / 58$ & Back & $1.5 \times 1.5$ & $\mathrm{BCC}$ & \\
\hline 24 & $\mathrm{~F} / 53$ & Back & $2.0 \times 2.0$ & EIC & Partial necrosis in 1 flap \\
\hline
\end{tabular}

F, female; M, male; SCC, squamous cell carcinoma; EIC, epidermal inclusion cyst; BCC, basal cell carcinoma. 

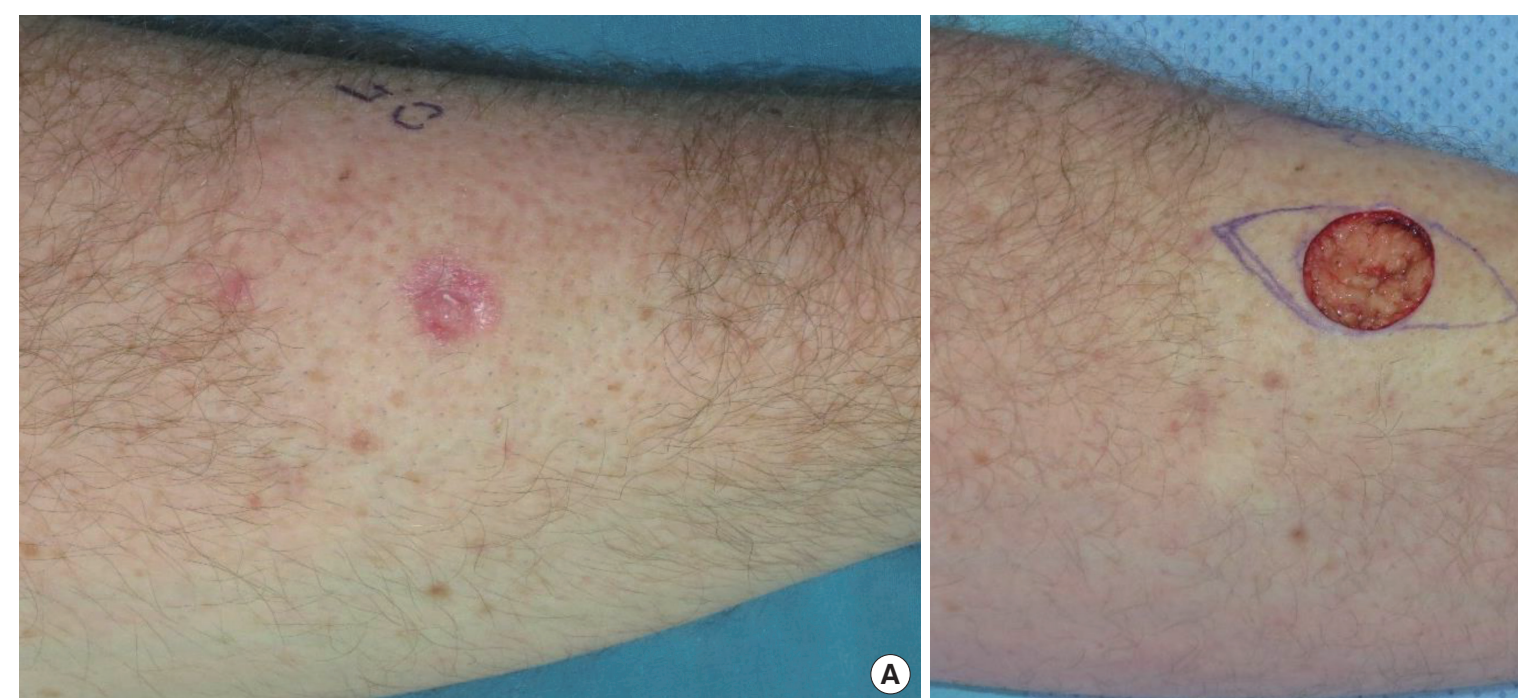

(A)
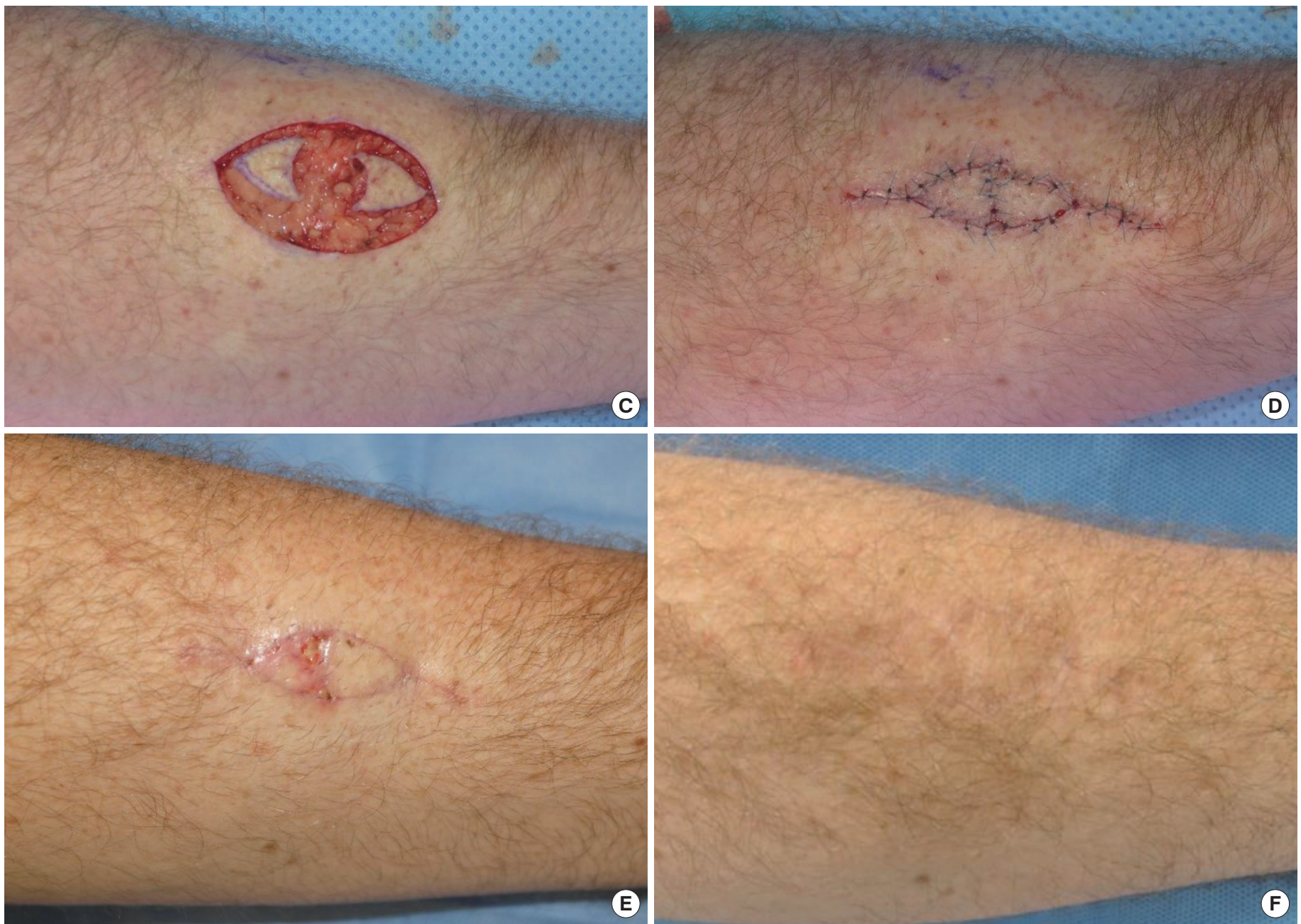

Fig. 1. A 58-year-old male patient presented with basal cell carcinoma in the central region of his forearm. (A) Preoperative skin lesion. (B) Design of small bilateral V-Y advancement flaps. (C) Intraoperative view, bilateral V-Y advancement flaps. (D) Immediate postoperative view. (E) All partially necrotized flaps healed within 3 weeks with conservative care. (F) Postoperative view at 3 months. 

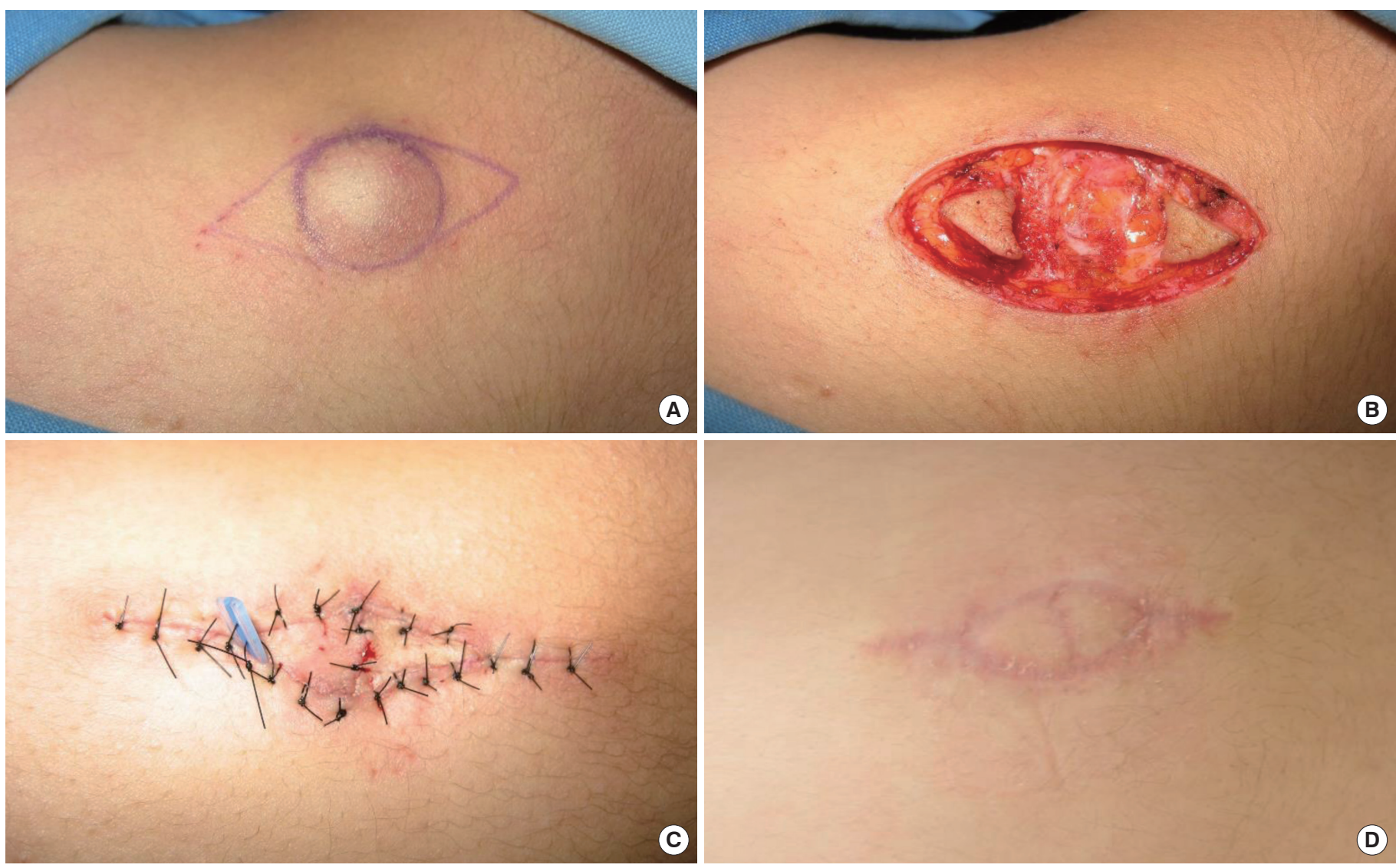

Fig. 2. Excision of a back epidermal inclusion cyst in a 28 -year-old male patient. (A) Preoperative design. (B) Flap elevation. (C) Immediate postoperative view. (D) Postoperative view at 1.5 months.

\section{Case 1: forearm}

A 58-year-old male patient presented with basal cell carcinoma in the central region of his forearm. The $1.9 \times 0.8-\mathrm{cm}$ lesion was totally excised with a safety margin of $3 \mathrm{~mm}$. A bilateral V-Y advancement flap was designed according to the defect size. The apex of the triangular flap was determined as 2 times the radius of the defect. Minimal dissection in the subcutaneous plane was sufficient in the forearm. First, midline sutures between the 2 flaps were made. The donor site was then closed and the remaining flap margins were sutured. The scar was well hidden and no depressions or contour irregularities were observed at 3 months postoperatively (Fig. 1).

\section{Case 2: back}

Often skin overlying infected epidermal inclusion cyst is affected repetitively. Therefore, it needs to be removed to avoid post-operative wound problems. An inflamed mass measuring approximately $2 \times 2 \mathrm{~cm}$ in a 28-year-old male patient was excised with the overlying skin, and the subsequent skin defect was covered by bilateral $\mathrm{V}-\mathrm{Y}$ advancement flaps. No wound margin compromise or infection occurred, but the thick dermal tissue of the back tends to stretch, so a relatively visible scar was left (Fig. 2).

\section{Case 3: lower leg (posteromedial)}

Dermatofibroma in a 35-year-old female patient was treated with the same method. Even in the lower leg, medial and posterior aspects displayed relatively less tense subcutaneous tissue than the anterior and lateral aspects. Small flaps with a diameter less than 10 $\mathrm{mm}$ can be easily advanced with a reliable subcutaneous pedicle. Minimal undermining or dissection helps to preserve the vascularity of the flap (Fig. 3).

\section{Case 4: lower leg (anterolateral)}

A skin defect approximately $2.5 \times 2.5 \mathrm{~cm}$ in size occurred after the resection of squamous cell carcinoma of the right lateral lower leg in a 40-year-old male patient. A bilateral V-Y advancement flap was designed on a longitudinal axis. The flap showed congestive color at the patient's first outpatient visit after surgery. Two weeks after the operation, total necrosis was observed in 1 flap and covered with a skin graft (Fig. 4).

\section{RESULTS}

The follow-up period ranged from 3 to 36 months, with a mean 

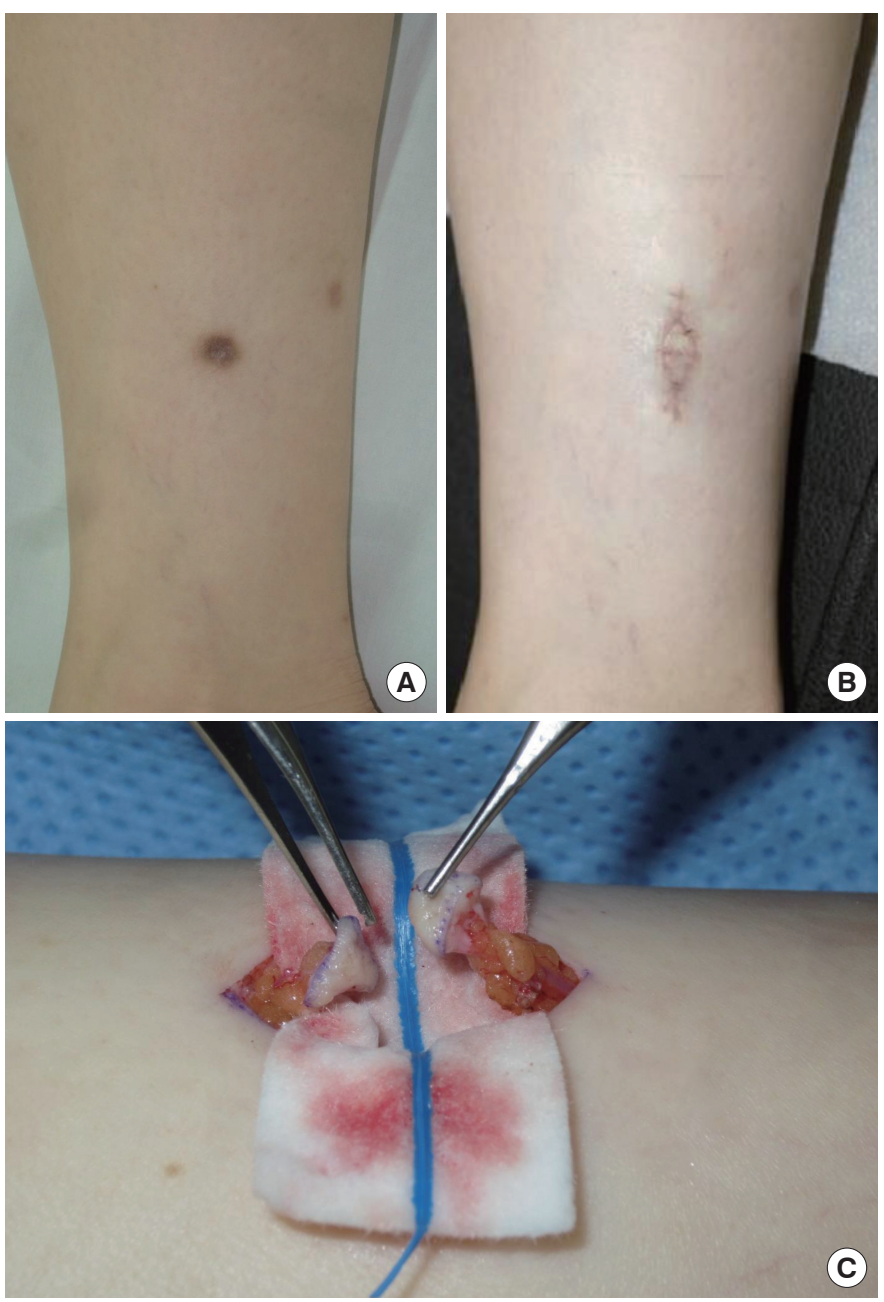

Fig. 3. Dermatofibroma in a 34-year-old female patient. (A) At presentation. (B) The flap completely healed without necrosis at 2 weeks postoperatively. (C) Two triangular flaps were elevated, while saving the thick subcutaneous fat and subcutaneous plexus.

follow-up duration of 11.7 months. During the follow-up period, partial flap necrosis occurred in 5 flaps (4 patients), but all healed secondarily. One case of complete loss of the flap occurred, and it was managed with a skin graft. All the other flaps fully survived without any complications.

It was notable that 5 of the 6 necrosis cases occurred in the anterolateral lower leg and paraspinal area. Another trend was that when the skin flap adjacent to an epidermal inclusion cyst was affected by an unresolved cutaneous infection, partial flap necrosis tended to occur at the sutured margin (2 out of 6 cases of necrosis). Contour deformities such as central depression and dog-ear deformities were not observed. In the subjective self-assessment using a 4-point scale, 5 of the 11 patients (45\%) reported being very satisfied, $4(36 \%)$ were satisfied, 1 patient reported that the outcome was tolerable, and only 1 patient was unsatisfied. The mean value of the vertigo symptom scale scores was 4.72 .
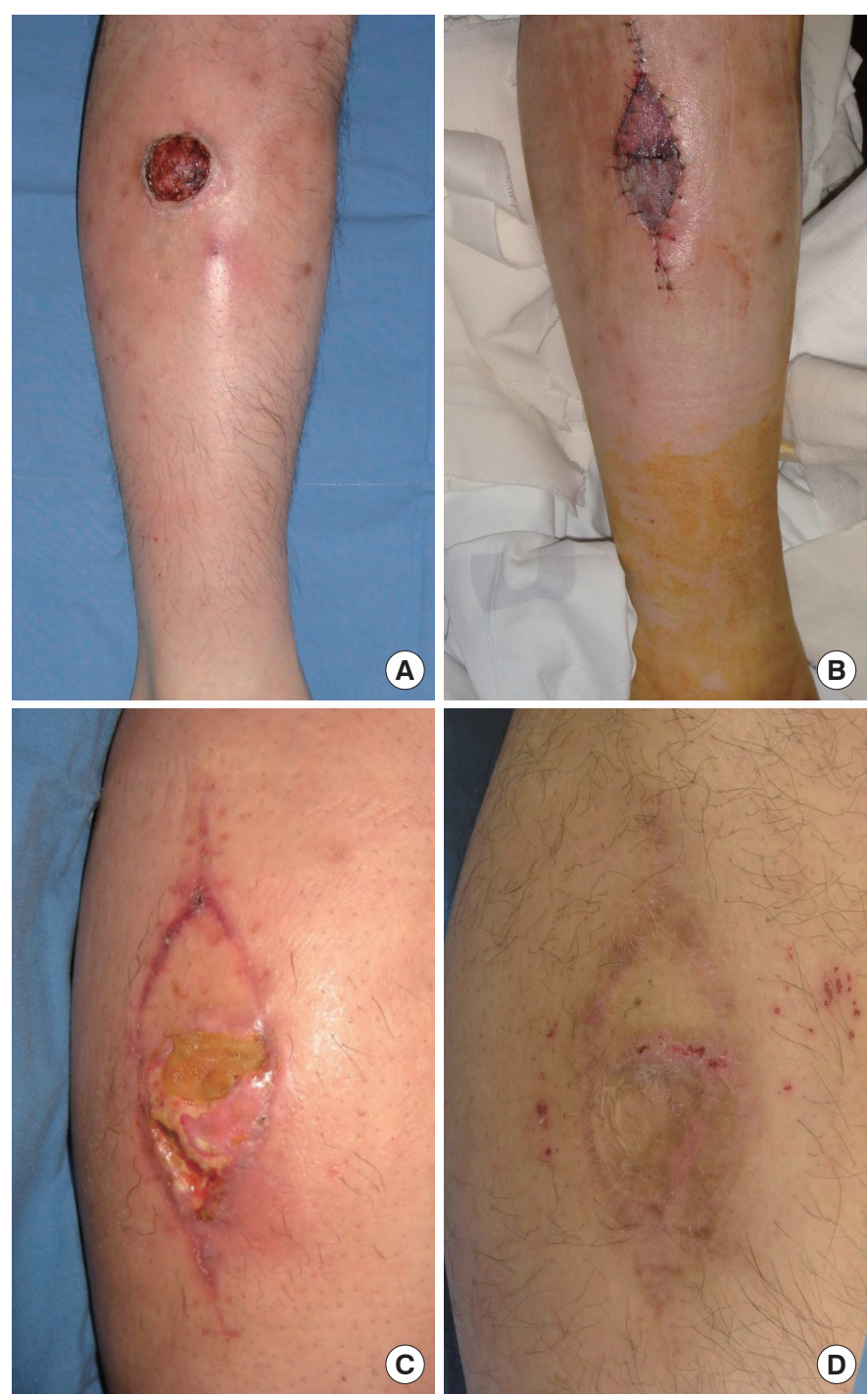

Fig. 4. Forty-year-old male with squamous cell carcinoma. (A) Preoperative skin lesion. (B) Three days postoperatively. (C) Two weeks postoperatively. Total loss of the caudal flap occurred. A skin graft was performed. (D) Final results at 2 months postoperatively.

\section{DISCUSSION}

A fusiform ellipse is the most common pattern used to close circular skin defects. However, in elliptical excisions, healthy skin is wasted and unnecessarily long scars can be created. According to a recent study, compared with the original defect size, a mean of $130 \%$ of healthy skin is wasted in this technique [6]. Central depression with peaking at either end of the wound is another problem, and many small flaps have been developed to avoid such unfavorable outcomes.

Bilateral V-Y advancement flaps are one of many options and have been mostly used for facial defects. Although applying bilateral V-Y advancement flaps after facial, trunk, and extremity skin 


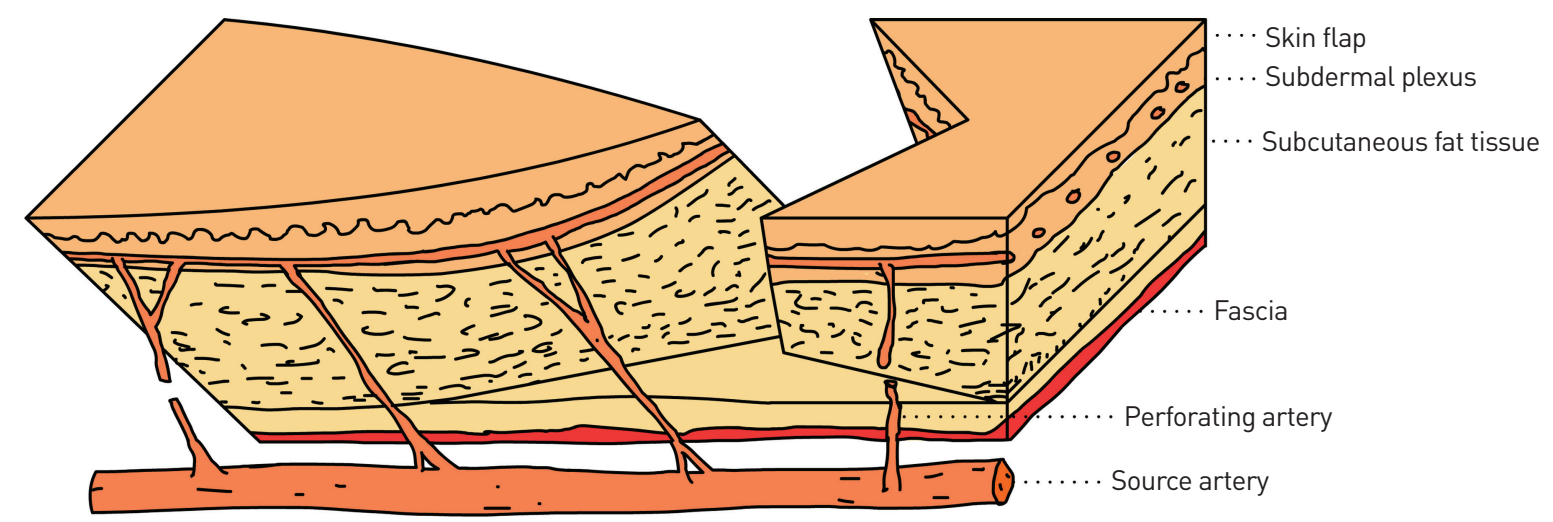

Fig. 5. Schematic diagram of the V-Y advancement flap. The subcutaneous flap pedicle includes perpendicularly oriented perforating vessels.

tumor excision has been suggested [7], the relatively poor vascularity and different thickness of the subcutaneous tissue in the extremities have not received adequate consideration. Generally, these flaps are not used in the extremities as often as they are used in the face. One reason for this is the presence of less skin redundancy and more tension near the joint area. A more practical explanation could be based on the different thicknesses of the subcutaneous tissue, as the gliding potential of local advancement flaps relying on subcutaneous circulation is restricted by the underlying thickness of the subcutaneous fat layer (Fig. 5). The larger the defect, the more advancement is required, as well as a longer subcutaneous pedicle. Nakajima et al. [8] classified arteries in the skin and subcutaneous adipofascial tissue into 6 types of 3-dimensional structures. In their study, the extremities were found to be dominated by type $\mathrm{V}$ structures, in which fine septocutaneous perforators supply the overlying skin. The major portion of the back is covered with type VI structures, in which fine musculocutaneous perforators are the source of the cutaneous and subcutaneous vascular supply. These type $\mathrm{V}$ and VI structures show little axiality, and the source artery diverges in the deep adipofascial layer or subfascial layer and courses perpendicularly, reaching the subdermal plexus. Due to its low axiality and the relatively perpendicular course of the perforating vessels, the thickness of the subcutaneous layer matches the potential length of the subcutaneous pedicle in the extremities and back.

With this in mind, we applied bilateral V-Y advancement flaps to treat various small defects of the trunk and extremities, aiming to identify site-specific precautions. Even with the low axiality of the vascular network, the sufficient subcutaneous thickness makes the upper extremities and thigh excellent places to apply this technique. If the cutaneous flap is not affected by an infection, the back is also a relatively good candidate, although its thick dermis is apt to result in more visible scars [9]. The lower leg, especially the anterolateral side, was a challenging site, as the circulation and subcutaneous thickness were perceived to be inadequate to sustain local subcutaneous flaps.
Even in the lower leg, defects under $10 \mathrm{~mm}$ in diameter mostly can be closed primarily. Larger defects (diameter over $35 \mathrm{~mm}$ ) are managed by split skin grafts, free flaps, or local flaps that incorporate nearby perforators $[10,11]$. Small lower leg defects between 10 and $35 \mathrm{~mm}$ are candidates for a local subcutaneous flap, including bilateral V-Y advancement flaps. Most of these flaps use a randompattern subcutaneous pedicle $[3,4,12,13]$, and attempts have been made to include the deep fascia, hoping for better perfusion. Hallock [14] reported so-called random fasciocutaneous flaps that included adequate deep fascia for small or moderate-sized defects. They asserted that the integrity of the subcutaneous circulation was ensured if the deep fascia remained with the cutaneous flap. However, a deep pedicle reduces the mobility of the flap, particularly when there is not enough subcutaneous fat. Penington and Mallucci [5] reported a random-pattern fasciocutaneous V-Y island flap that had a fascial pedicle on only 1 side of the V-flap. A skin paddle with improved mobility was supplied by the perifascial plexus and the perforators that joined that plexus to the subdermal plexus. Still, all of these techniques require wide undermining or deep dissection under and over the fascial layer to mobilize the flap. Thus, they are quite time-consuming and cannot be easily performed in an outpatient setting.

Therefore, making the dissection deeper does not always lead to positive results. Instead of going deeper, we should focus on the vascular characteristics of the anterolateral lower leg. As is well known, the angiosomes of the lower leg arise from 3 main vessels: the anterior tibial, posterior tibial, and peroneal arteries. The skin branches of the anterolateral surface of the leg are provided by the anterior tibial and peroneal artery via muscle perforators or septocutaneous perforators. A vascular shedding zone exists between these 2 source arteries at the skin territory over the peroneus longus and brevis muscles. The peroneus muscle itself receives circulation from the anterior tibial artery proximally and the peroneal artery distally, and the border between these 2 angiosomes lies oblique to the muscles and longitudinal to the lower leg axis [15-17]. As discussed above, 
type $\mathrm{V}$ adipofascial perforators lack axiality and course perpendicular to the skin. Therefore, the scantiness of underlying perforators is clearly reflected in the vascular insufficiency for skin flaps in this area. All our failed flaps were located over this longitudinal vascular shedding zone with a longitudinal axis of advancement.

There are some ways to overcome the problems posed by the anterolateral lower leg. First, according to Blair et al. [18], the axis of an advancement flap at the limb should be perpendicular to the limb axis. As the limb is essentially circular, advancing the flaps in this way reduces the effective radius of the leg, thereby decreasing the distance of flap movement that is necessary to achieve closure. The oblique axis design also has advantages, as the apex of the flap lies in an area of sufficient laxity to allow closure of the secondary defect [11]. Furthermore, this change in the axis increases the chance of incorporating neighboring angiosomes in the flap, as the main source arteries are aligned longitudinally with its angiosomes, which show column-like territories. Secondly, unlike the face, the use of 2 flaps bilaterally is essential, because it halves the advancement needed from each flap to close the defect, allowing less tension with less need for dissection $[18,19]$. Lastly, for small local flaps, the main vascular network of the skin flap lies in the subcutaneous layer, so conserving the subcutaneous pedicle with sufficient fascial attachment is important [20-22]. The cross-sectional area of the skin flap, the subcutaneous pedicle, and the fascia attachment area should be the same or gradually increase, but should never decrease. In most of our cases, wide undermining was unnecessary and gentle release of the fibrous connections of the superficial fascial system sufficed for the transposition of the flap.

The main limitation of this study is its small sample size. Vascular studies of the whole body have been conducted previously by many authors, but the main focus has been on skin flap circulation or perforating vessels and the associated perforasomes. The vertical and axial distribution of the subcutaneous plexus pattern in different parts of the body should be analyzed to support a comprehensive understanding of the reliability of these random subcutaneous pedicle flaps.

In conclusion, bilateral V-Y advancement flap coverage in the extremities is very useful, as it is in the face. The thigh, upper arm, forearm, and back are suitable regions, but the anterolateral lower leg is a poor candidate for reconstruction with these flaps, due to its thin subcutaneous fat and vascular shedding zone, both of which increase the risk of poor subcutaneous pedicle circulation. Because the defect is covered by 2 triangular flaps that would otherwise be discarded, contour deformities are minimized and wide undermining or a fascial back-cut is not needed to ensure the mobility of the flap. Although a triangular scar is noticeable in the early recovery period, it generally fades away within 6 months after the operation. Last but not least, this technique can be easily performed in an outpatient setting.

\section{PATIENT CONSENT}

Patients provided written consent for the use of their images.

\section{REFERENCES}

1. Jackson IT. Local flaps in head and neck reconstruction. 2nd ed. St. Louis, MO: Quality Medical Publishing, Inc; 2007.

2. Omidi M, Granick MS. The versatile V-Y flap for facial reconstruction. Dermatol Surg 2004;30:415-20.

3. Barron JN, Emmett AJ. Subcutaneous pedicle flaps. Br J Plast Surg 1965; 18:51-78.

4. Emmett AJ. The closure of defects by using adjacent triangular flaps with subcutaneous pedicles. Plast Reconstr Surg 1977;59:45-52.

5. Penington AJ, Mallucci P. Closure of elective skin defects in the leg with a fasciocutaneous V-Y island flap. Br J Plast Surg 1999;52:458-61.

6. Tilleman TR, Neumann MH, Smeets NW, et al. Waste of skin in elliptical excision biopsy of non-melanomatous skin cancer. Scand J Plast Reconstr Surg Hand Surg 2006;40:352-6.

7. Kwon KH, Lee DG, Koo SH, et al. Usefulness of v-y advancement flap for defects after skin tumor excision. Arch Plast Surg 2012;39:619-25.

8. Nakajima H, Minabe T, Imanishi N. Three-dimensional analysis and classification of arteries in the skin and subcutaneous adipofascial tissue by computer graphics imaging. Plast Reconstr Surg 1998;102:74860.

9. Dunkin CS, Pleat JM, Gillespie PH, et al. Scarring occurs at a critical depth of skin injury: precise measurement in a graduated dermal scratch in human volunteers. Plast Reconstr Surg 2007;119:1722-32; discussion 33-4.

10. Dixon AJ, Dixon MP. Reducing opposed multilobed flap repair, a new technique for managing medium-sized low-leg defects following skin cancer surgery. Dermatol Surg 2004;30:1406-11.

11. Niranjan NS, Price RD, Govilkar P. Fascial feeder and perforator-based $\mathrm{V}-\mathrm{Y}$ advancement flaps in the reconstruction of lower limb defects. $\mathrm{Br}$ J Plast Surg 2000;53:679-89.

12. Trevaskis AE, Rempel J, Okunski W, et al. Sliding subcutaneous-pedicle flaps to close a circular defect. Plast Reconstr Surg 1970;46:155-7.

13. Dufourmentel CTS. The kite flap. In: Hueston JT, editor. Transactions of the Fifth International Congress of plastic and reconstructive surgery; 1971 Feb 22-26. Melbourne, AU: Butterworth and Co. Ltd.; 1971. p. 1123-4.

14. Hallock GG. The random fasciocutaneous flap for upper extremity coverage. J Hand Surg Am 1992;17:93-101.

15. Zbrodowski A, Gumener R, Gajisin S, et al. Blood supply of subcutaneous tissue in the leg and its clinical application. Clin Anat 1995;8: 202-7.

16. Taylor GI, Pan WR. Angiosomes of the leg: anatomic study and clinical implications. Plast Reconstr Surg 1998;102:599-616; discussion 7-8.

17. Taylor GI, Corlett RJ, Dhar SC, et al. The anatomical (angiosome) and clinical territories of cutaneous perforating arteries: development of 
the concept and designing safe flaps. Plast Reconstr Surg 2011;127:144759.

18. Blair JW, Bainbridge LC, Knight SL. Double V-Y advancement flaps in the reconstruction of skin defects of the anterior lower limb. Br J Plast Surg 1993;46:644-6.

19. Kalus R, Zamora S. Aesthetic considerations in facial reconstructive surgery: the V-Y flap revisited. Aesthetic Plast Surg 1996;20:83-6.

20. Verdolini R, Dhoat S, Bugatti L, et al. Opposed bilateral transposition flap: a simple and effective way to close large defects, especially of the limbs. J Eur Acad Dermatol Venereol 2008;22:601-5.

21. Cecchi R, Bartoli L, Brunetti L, et al. Leg defect reconstruction with double hatchet flaps: report of eight cases. Dermatol Ther 2016;29:21921.

22. Cecchi R, Bartoli L, Brunetti L. Double helix flaps for lower leg defects: report of 4 cases. J Cutan Aesthet Surg 2013;6:164-5. 